\title{
Relações entre gêneros na teorização curricular tradicional, crítica e pós-crítica
}

\author{
Relations between genders in traditional, critical and post-critical \\ curricular theorization
}

\section{Relaciones entre géneros en la teorización curricular tradicional, crítica y post-crítica}

\section{Eleta de Carualho Freire ${ }^{1}$}

Universidade Federal de Pernambuco, Centro de Educação e Mestrado Profissional em Ensino de História, Professora; Pesquisadora do Núcleo de Pesquisa em História da Educação e Ensino de História (NEPHEPE)

Resumo: Esta pesquisa versa sobre as relações entre gênero e educação, nomeadamente sobre gênero e currículo, objetivando compreender o lugar ocupado pelas relações sociais de gênero na teorização curricular. Trata-se de uma investigação teórica que buscou apoio em três diferentes fases formadoras do campo de estudos sobre o currículo e do campo dos estudos de gênero. A pesquisa toma como objeto de análise os pressupostos da teorização curricular - tradicional, crítica e pós-crítica - em seus contextos de emergência e desenvolvimento, com vistas a identificar distanciamentos e aproximações entre currículo e gênero nesses estudos. Os resultados revelam que, embora o currículo escolar tenha sido desde sempre atravessado por relações entre os gêneros, tais relações estiveram ausentes da teorização tradicional ou não crítica em razão de sua vinculação ao paradigma da racionalidade técnicocientífica e à consequente tese da neutralidade e objetividade do currículo. Estiveram ausentes também da fase inicial da teorização crítica, por sua centralidade na categoria classe social. Inserem-se no discurso curricular na segunda fase dessa teorização a partir do entendimento de que a cultura, como elemento constituido e constituinte de diferenças, também institui desigualdades, entre as quais se incluem as desigualdades de gênero. Assim, a teorização crítica, por meio da corrente da resistência, anuncia o atravessamento do currículo pelas diferenças de gênero e etnia, entre outras, aproximando-se da perspectiva multiculturalista. A teorização pós-crítica, ao atribuir centralidade à linguagem, aponta novas formas de olhar as relações entre gênero e educação, mais especificamente entre gênero e currículo.

Palavras-chave: Currículo e gênero. Gênero e educação. Teorização curricular.

Abstract: This research deals with the relations between gender and education, especially on gender and curriculum, in order to understand the place occupied by gender social relations in curricular theorization. This is a theoretical research that sought support in three different phases that form the field of study on

Doutora e Mestre em Educação pela Universidade Federal de Pernambuco; https://orcid.org/0000-0003-2283-9774; http:// lattes.cnpq.br/1696659914933898. 
the curriculum and in the field of study gender. The research takes as an object of analysis the assumptions of curricular theorization - traditional, critical and post-critical - in its emergency and development contexts, with a view to identifying distances and approaches between curriculum and gender in these studies. The results show that although the school curriculum has always been crossed by gender relations, such relationships have been absent from traditional or non-critical theorization because of its linkage with the paradigm of technical-scientific rationality and the consequent thesis of the neutrality and objectivity of the curriculum. They were also absent from the initial phase of critical theorization, because of its centrality in the social class category. They are inserted in the curricular discourse in the second phase of this theorization based on the understanding that culture, as a constituted and constituent element of differences, is also an institution of inequalities, among which include gender inequalities. Thus, critical theorizing, through the resistance chain, announces the crossing of the curriculum by the differences of gender and ethnicity among others, approaching the multiculturalist perspective. Post-critical theorizing, by attributing centrality to language, points to new ways of looking at the relations between gender and education, more specifically between curriculum and gender.

Keywords: Curriculum and gender. Gender and education. Curricular theorization.

Resumen: Esta investigación versa sobre las relaciones entre género y educación, especialmente sobre género y currículo, con el objetivo de comprender el lugar ocupado por las relaciones sociales de género en la teorización curricular. Se trata de una investigación teórica que buscó apoyo en tres diferentes fases formadoras del campo de estudios sobre el currículo y el campo de estudios de género. La investigación toma como objeto de análisis los presupuestos de la teorización curricular tradicional, crítica y post-crítica - en sus contextos de emergencia y desarrollo, con miras a identificar distanciamientos y acercamientos entre currículo y género en esos estudios. Los resultados revelan que, aunque el currículo escolar ha sido siempre atravesado por relaciones entre los géneros, tales relaciones estuvieron ausentes de la teorización tradicional o no crítica en razón de su vinculación al paradigma de la racionalidad técnico-científica ya la consiguiente tesis de la neutralidad y objetividad del currículo. También estuvieron ausentes de la fase inicial de la teorización crítica, por su centralidad en la categoría social. Se inserta en el discurso curricular en la segunda fase de esta teorización a partir del entendimiento de que la cultura, como elemento constituido y constituyente de diferencias, es también instituyente de desigualdades, entre las que se incluyen las desigualdades de género. Así, la teorización crítica, a través de la corriente de la resistencia, anuncia el atravesamiento del currículo por las diferencias de género y etnia, entre otras, aproximándose a la perspectiva multiculturalista. La teorización post-crítica, al atribuir centralidad al lenguaje, apunta nuevas formas de mirar las relaciones entre género y educación, más especificamente, entre género y currículo.

Palabras clave: Currículo y género. Género y educación. Teorización curricular.

Recebido em 14 de fevereiro de 2018 Aceito em 25 de novembro de 2018 Publicado em 19 de março de 2019 


\section{GÊNERO NA TEORIZAÇÃO CURRICULAR: O INÍCIO DA CAMINHADA}

Os estudos sobre o currículo escolar são relativamente recentes se comparados à sua existência como ferramenta pedagógica. A palavra currículo deriva da palavra latina Scurrere que se refere a correr, corrida, carreira, curso, de onde advém sua vinculação a curso a ser seguido, apresentado. Portanto, considerando-se a etimologia da palavra, o currículo corresponde a uma sequência de conteúdos apresentados para estudo. Nos séculos XIV e $X V$, o termo curso passa a ser utilizado, com variedade semântica na linguagem universitária em línguas como o português, o francês, o inglês, entre outras. Já o termo currículo aparece mais tardiamente, em 1682, com a palavra curricule em inglês, sendo registrada com o sentido de cursinho. A partir de 1824, a palavra curriculum, também em inglês, passa a denominar curso de aperfeiçoamento ou estudos universitários, também chamados de course. No século XX, a palavra curriculum migra da Inglaterra para os Estados Unidos, sendo empregada com o sentido de curriculum vitae, e nos anos 1940 é aportuguesada no Brasil (TERIGl, 1996; GO0DSON, 2002; BERTICELLI, 2003; PACHECO, 2005).

Não obstante a convivência histórica entre as realidades curricular e escolar, o termo currículo foi utilizado para denominar diferentes elementos da prática escolar em diferentes épocas, revelando seu aspecto polissêmico, principalmente a partir da institucionalização da escola no final do século XIX. A polissemia do termo atravessou toda sua trajetória e ainda suscita discussões em torno do seu significado. Assim, de acordo com Pacheco (2005), para conceituar currículo, faz-se necessário aproximar-se do contexto em que este se situa e das pessoas que nele interferem.

Desse modo, a coexistência entre a realidade curricular e a realidade escolar foi historicamente marcada por concepções diversas, abordagens distintas e teorizações que expressam o momento histórico do qual emergem as várias formas de conceber o contexto socioeconômico e político cultural e, em especial, no qual se assentam os projetos de sociedade. Nesse sentido, entendemos que a reflexão sobre esse objeto social implica compreender o itinerário seguido na formulação de um campo de estudos, cuja teorização esteve ancorada em diferentes paradigmas, e cuja vinculação às relações de poder pode ser observada desde sua gênese.

Cabe-nos sublinhar, inicialmente, que o currículo é aqui compreendido como terreno de criação, recriação e difusão da cultura, de modo que abarca o conjunto das experiências de ensino e de aprendizagem a que os estudantes estão expostos na escola, por meio das práticas docentes formais, das interações sociais e das vivências com representações, ritos e comportamentos. Nesse sentido, o currículo "constitui o núcleo do processo institucionalizado 
de educação. 0 nexo íntimo e estreito entre educação e identidade social, entre escolarização e subjetividade [...]" (SILVA, 1996, p. 179-180).

Assim, compreendemos que o currículo implica escolhas, portanto alguns elementos da cultura ganham relevo em seu interior, enquanto outros são excluídos ou auferem menos evidência. Desse modo, a ausência ou a presença de alguns desses elementos no currículo - com maior ou menor ênfase - resulta das relações sociais, em especial das relações de poder vivenciadas na sociedade. Por outro lado, nesta análise rejeitamos a ideia de validade universal do currículo, reconhecendo que como construção histórico-social o currículo oferece as bases para que elementos da cultura possam ser problematizados e tomados como objetos de ensino e de aprendizagem, a exemplo das relações sociais de gênero.

A construção do conceito de gênero, por sua vez, sugere um relato não linear, posto que incorpora a complexidade inerente às relações sociais, envolve a posição variável das mulheres na história e a pluralidade de movimentos sociais que originaram diferentes compreensões a respeito das relações entre os sexos, além de diferentes construções sobre o gênero. 0 gênero diz respeito às relações entre pessoas, às representações criadas pela sociedade com relação ao que é masculino e ao que é feminino e tem referência também nos artefatos culturais identificados historicamente como masculinos ou femininos. Assim, categorias percebidas como masculinas ou femininas podem variar de acordo com a cultura e o momento histórico. Desse modo, gênero diz respeito a "uma maneira de indicar as 'construções sociais': a criação inteiramente social das idéias sobre os papéis próprios aos homens e às mulheres." (SCOTT, 1990, p. 7). Como afirmam Samara et al. (1997, p. 39):

[...] gênero é uma construção social e cultural sustentada pela diferença do feminino e do masculino. Sendo assim, a relação entre os sexos não é, portanto, um fato natural, mas sim uma interação social construida e remodelada incessantemente, nas diferentes sociedades e períodos históricos.

Por conseguinte, a identidade de gênero dos sujeitos é constituída pelas ideias que socialmente foram se construindo com relação ao que é masculino e ao que é feminino e que culturalmente foram sendo transmitidas, considerando-se o aspecto complementar das relações de gênero. Como afirma Carvalho (2007, p. 38), essa construção "se dá na infância e ao longo da vida. As relações de gênero são construídas, desconstruídas, reconstruídas; gênero é processo, performance e estrutura - estável, mas não imutável." Constitui uma construção do sujeito histórico que varia de uma sociedade para outra em diferentes momentos. Trata-se, por sua vez, de uma construção cultural da qual emerge sua estreita relação com o currículo. 
Nessa perspectiva, neste artigo nos propomos a recuperar as contribuições dos debates no campo do currículo, na busca por compreender o lugar que as relações sociais de gênero ocupam nos estudos curriculares. Trata-se de apreender as contribuições desses estudos para as mudanças operadas no entendimento sobre a interdependência entre currículo e gênero.

Para isso, buscamos apoio na categorização da teorização curricular como a entende Silva $(2000,2007)$ entre outros, para responder ao seguinte questionamento: qual o espaço reservado, na teorização curricular - tradicional, crítica e pós-crítica -, para as discussões sobre as relações sociais de gênero? A resposta a essa questão remete à necessidade de compreender a forma como a teorização no campo do currículo estaria envolvida com questões de poder, como apreende elementos da cultura e em que medida a (des)construção e reconstrução das relações entre os gêneros teria sido incorporada às análises dos processos formativos vivenciados no interior da escola.

\section{GÊENERO NA TEORIZAÇÃO CURRICULAR NÃO CRÍTICA: 0 LEGADO DA RACIONALIDADE TÉCNICO-CIENTÍFICA}

Os estudos sobre o currículo, desenvolvidos com base nas teorias educacionais tradicionais ou não críticas têm suas análises marcadas pelo distanciamento entre os sujeitos produtores do fenômeno educativo e o próprio fenômeno. Trata-se da separação entre a teoria e a sociedade mais ampla, que, de acordo com Horkheimer (1991, p. 39) desconsidera que: "[...] os fatos que os sentidos nos fornecem são pré-formados de modo duplo: pelo caráter histórico do objeto percebido e pelo caráter histórico do órgão perceptivo. Nem um nem outro são meramente naturais, mas enformados pela atividade humana."

Assim, podemos inferir que, em decorrência do legado do paradigma da racionalidade científica positivista adotada na investigação social, os estudos curriculares referenciados nessa lógica de produção do conhecimento caracterizam-se pela ausência de contextualização sócio-histórica, pela preponderância da quantificação e descrição de dados, pela separação entre indivíduo e sociedade, pela desconsideração da unidade teoria-prática e da possibilidade de ressignificação da escola pelos sujeitos que a integram.

Dessas propriedades resulta a teorização curricular tradicional ou não crítica, caracterizada por sua pretensão à neutralidade, à cientificidade supostamente desinteressada, logo sem implicações com relações de poder. Trata-se de uma teorização marcada pelo predomínio da dimensão técnica na análise dos fenômenos educativos em geral e, em particular, do currículo. Nessa perspectiva, o currículo é compreendido como uma área 
técnica, voltada à descrição de procedimentos, métodos e técnicas de ensino e marcada pela ideia de neutralidade e objetividade na organização dos componentes curriculares, na escolha dos conteúdos de ensino, das atividades pedagógicas e das formas de avaliação.

De tal modo, o modelo de currículo proposto nas primeiras décadas do século $X X^{2}$ voltado para a economia, propõe que especialistas do sistema educacional procedam ao levantamento das habilidades necessárias às atividades profissionais da época, definam com precisão os objetivos a serem alcançados e elaborem instrumentos de medição para o controle das aprendizagens, ${ }^{3}$ de forma a atender ao desenvolvimento econômico.

Para Tyler (1974), o currículo é concebido como programa educacional que deveria ser planejado com base em princípios orientadores de quatro fases consideradas básicas: a definição dos objetivos, a seleção das experiências de aprendizagem, a organização das experiências de aprendizagem e a avaliação. Trata-se de um conjunto de técnicas cuidadosamente planejadas que parece se situar no plano da realidade idealizada, harmônica, não problemática, logo, não problematizada, e que não busca compreender os vínculos entre a escola e o contexto socioeconômico e político-cultural mais amplo. Assim, de acordo com Giroux (1986, p. 105):

\footnotetext{
[...] falta na visão tradicional a noção de que a cultura se refere a processos específicos que envolvem relações antagônicas vivenciadas por diferentes grupos sócio-econômicos, com diferente acesso aos meios de poder e uma resultante capacidade desigual para produzir, distribuir e legitimar seus princípios compartilhados e suas experiências de vida.
}

Desse modo, a teorização curricular não crítica, ao desconsiderar a dimensão dinâmica de (re)criação da cultura na constituição da sociedade, distancia-se das questões sociais envolvidas na elaboração e vivência das experiências curriculares e, em consequência, não incorpora questões relativas às relações entre classes, etnias, religiões e sexos vivenciadas no interior da escola.

Observamos, entretanto, que o contexto social de emergência da teorização curricular não crítica - início do século XX - já conta com formas de organização social das mulheres, expressas mediante movimentos de libertação iniciados no Ocidente no século XIX. Como exemplo destacamos as campanhas pela liberalização do aborto, pela igualdade de salários, pelo fim da discriminação sexual, pelo direito à licença-maternidade e ao voto, tendo este último sido conquistado em alguns países ainda no século XIX, ampliando-se para outros 
no século XX. A conquista do direito ao voto pelas mulheres se deu na Suécia em 1862, na Noruega em 1913, na Dinamarca em 1915, na Alemanha em 1918, na Holanda, Bélgica, Áustria, Luxemburgo, Polônia, Checoslováquia, Grécia, México e Inglaterra em 1919, nos Estados Unidos em 1924, em Portugal em 1931, no Brasil em 1932, na França em 1945, na Itália em 1946 e na Argentina em 1950 (KÄPPELI, 1991; ERGAS, 1991).

No entanto, as representações sobre a mulher construidas nesse período estão ancoradas no paradigma naturalista ${ }^{4}$ e no paradigma da racionalidade científica. Além disso, retratam as ideias, as crenças, os ensinamentos, os estudos e a ideologia dominante nesse período histórico. De acordo com Almeida (1998), o modelo teórico positivista adotado nos estudos sobre a mulher à época, referenda a tese de sua inferioridade biológica e intelectual e difunde-se por meio da literatura, das artes e da ciência, especialmente da medicina e da psiquiatria.

A educação, por sua vez, reflete esse modelo, inicialmente negando à mulher o acesso à escola e, mais tarde, estabelecendo a separação dos prédios e a escolha do professor por sexo; a organização das salas de aula e a seleção de conteúdos de ensino distintos para meninos e meninas. Assim, a organização educacional é marcada pela distinção entre os gêneros e em desfavor das mulheres.

Esse conjunto de elementos, no entanto, não é reconhecido como componente das práticas curriculares, uma vez que, de acordo com o enfoque tradicional, ao currículo diz respeito apenas a organização dos componentes curriculares, a escolha dos conteúdos de ensino, as atividades pedagógicas e a avaliação. Ou seja, por ser tratado como uma área puramente técnica, o currículo é compreendido como neutro, objetivo e sem vinculação com o social.

Dessa forma, a noção de natureza, tida como determinante dos comportamentos masculino e feminino pelo paradigma da racionalidade científica, influenciou os primeiros estudos sobre o currículo, em cuja formulação se desconsidera que a diferença entre os gêneros resulta das relações patriarcais predominantes na sociedade e na escola à época. Essa noção passou a justificar, durante décadas, a posição social de homens e de mulheres e, como diz Pucci (2003, p. 18), por não captar o poder ativo e constitutivo do sujeito na construção do mundo, o positivismo "acabou como cúmplice de uma política passiva e contemplativa que aceitava o mundo como um dado, como uma realidade pronta."

Dessa forma, podemos deduzir que o paradigma naturalista, em evidência no início do século XX, em consonância com o modelo positivista, predominante na teorização curricular não crítica, estaria à época apoiando a omissão das questões sociais nos estudos

\footnotetext{
40 paradigma naturalista apoia a ideia de que as diferenças - étnicas, de gêneros, de capacidades - seriam determinadas biologicamente e não socialmente produzidas. Seriam, portanto, do domínio do individuo e justificariam os diferentes comportamentos e desempenhos dos sujeitos.
} 
sobre o currículo, em especial as relações de gênero situadas no campo da crítica social iniciada nos anos 1960 com as teorias educacionais críticas.

\section{GÊNERO NA TEORIZAÇÃO CRÍTICA: A INSERÇÃO DA CULTURA COMO CATEGORIA ANALÍTICA NOS ESTUDOS CURRICULARES}

A produção de estudos curriculares da segunda metade do século XX conta com contribuições de diferentes campos do saber e enfrenta debates diversos que revelam continuidades e descontinuidades nos discursos da época. Desse modo, os debates sobre o currículo na perspectiva da teoria crítica, iniciados nos anos 1960, não constituem um bloco homogêneo. Abrangem a corrente reprodutivista, que compreende a escola como instância de reprodução da sociedade capitalista, e a corrente da resistência, cuja análise dos fenômenos educacionais aponta para possibilidades de contraposição ao discurso hegemônico e de emancipação social.

A primeira compreende as teorias da reprodução social: Teoria da Escola enquanto Aparelho Ideológico do Estado (AIE) de Louis Althusser (1969) e a Teoria da Escola Dualista de Christian Baudelot e Roger Establet (1971); e as teorias da reprodução cultural: Teoria do Sistema de Ensino enquanto Violência Simbólica de Pierre Bourdieu e Jean Claude Passeron (1970) e a Teoria dos Códigos de Basil Bernstein (1975). A corrente da resistência, por sua vez, envolve os estudos de Paulo Freire (1987, 1989), Michael APPLE (2002, 2006) e Henri Giroux (1986), entre outros.

A teorização educacional crítica, como o próprio nome indica, caracteriza-se pela abordagem crítica dos processos educacionais e da escola como instituição social responsável pela difusão da cultura. Em contraposição às teorias não críticas, essa corrente dá origem a um pensamento de ruptura com as análises que tentavam explicar as razões do insucesso escolar das crianças oriundas das camadas populares, partindo da ideia de consenso social e de neutralidade do currículo.

Possibilita também submeter os processos educativos desenvolvidos na escola à análise crítico-reflexiva, tornando possivel conhecer as relações entre escola e sociedade e, ao mesmo tempo, desvendar os mecanismos de controle próprios às relações sociais de poder. Esses estudos representam uma tomada de consciência sobre a natureza social da escola, compreendida em suas relações com a cultura e atravessada por relações de poder.

Ao incorporar a categoria "cultura" à análise da relação entre a escola e a sociedade capitalista, as teorias educacionais críticas oferecem elementos para compreensão e discussão a respeito dos vários segmentos sociais formadores dessa instituição social 
e dos processos educativos que nela se desenvolvem. Nessa perspectiva, a escola passa a ser compreendida como espaço da cultura, enquanto esta última se constitui um cenário das práticas sociais mais amplas que se estabelecem em uma relação dialética entre o comportamento de classe e os condicionantes sociais. Como afirma Silva (2003, p. 9), "é impossivel teorizar a sociedade, teorizar a educação, sem uma compreensão das formas e processos pelos quais ambos são constituídos culturalmente."

Assim, a cultura tomada como categoria nas análises sobre o currículo pela teorização crítica possibilita não apenas olhar a escola de diferentes pontos de vista, mas também ampliar esse olhar para os sujeitos que nela atuam. No entanto, com relação à consideração dos estudos sobre gênero no currículo escolar, pode-se dizer que as teorias educacionais críticas tratam o fenômeno das relações de gênero e os sujeitos dessas relações sob diferentes contornos e, dessa forma, apresentam diferenças em suas abordagens.

De tal modo, a corrente da reprodução social, ao colocar no centro de sua análise a desigualdade entre classes sociais, não envolve na formulação de sua crítica a produção das desigualdades pautadas nas diferenças culturais. Em consequência, não contempla o gênero como categoria nas análises dos fenômenos educacionais, talvez por considerar que, no bojo da resolução das desigualdades entre as classes sociais, estariam solucionadas as desigualdades entre os gêneros.

Assim, as teorizações produzidas por Althusser (1985), Baudelot e Establet (1971), ao tomarem o antagonismo entre as classes sociais como cenário e elegerem a categoria ideologia como central para suas análises, teriam deixado de considerar o patriarcado como forma de dominação que expressa relações de poder apoiadas nas diferenças culturais. Nesse caso, as relações sociais desiguais forjadas com referência nas diferenças de gênero não são problematizadas por essas teorias, da mesma forma que não são tratadas como elementos que atravessam as classes sociais e produzem desigualdades no interior de uma mesma classe.

Nessa perspectiva, não obstante as contribuições da teorização crítica para os estudos curriculares desde suas primeiras elaborações, com relação aos anseios sociais de construção de relações menos assimétricas entre os gêneros no currículo escolar, podemos inferir que a teorização crítica em sua primeira fase parece ter contribuído muito mais para a manutenção da invisibilização da mulher, na medida em que toma o patriarcado como não problemático e não problematizável.

A corrente da reprodução cultural, por sua vez, aponta a linguagem como veículo de reprodução dos valores, crenças e representações da sociedade burguesa, imposta à classe trabalhadora, por meio do habitus e do código, respectivamente. 
Para Bourdieu e Passeron (1982, p. 61), o habitus constitui "sistemas de disposições duráveis, estruturas estruturadas predispostas a funcionar como estruturas estruturantes, isto é, como princípio gerador e estruturador das práticas e das representações que podem ser objetivamente 'reguladas' e 'regulares'." Corresponde ao conjunto de disposições e princípios da estrutura social, interiorizados pelo sujeito, que regula as práticas sociais.

De outra parte, o código é compreendido como a gramática das classes sociais, o conjunto de regras implícitas apreendidas pelas pessoas das diferentes classes e que lhes permite distinguir os comportamentos aceitos dos não aceitos em contextos diversos. Abrange o conjunto de princípios regulativos daquilo que o sujeito faz e diz; define a escolha de significados e a forma de expressá-los nas interações sociais (BERNSTEIN, 1996).

Em suas primeiras elaborações, essa corrente, a exemplo da anterior, atribui à escola a responsabilidade pela reprodução da sociedade capitalista, tomando como categoria analítica a classe social; contudo as desigualdades produzidas com base nas diferenças culturais não são tratadas ou consideradas como objeto de crítica.

Essas diferenças, no entanto, estariam presentes na escola sendo veiculadas por meio das práticas e das comunicações que se desenvolvem através do currículo, cuja seleção de conteúdos estabelece diferentes saberes a serem ensinados a meninos e meninas. Entretanto, a distinção não se faz notar apenas nos conteúdos de ensino, as expectativas sobre as aprendizagens de alunos e alunas também são distintas, assim como a probabilidade de um melhor desempenho dos meninos em determinadas áreas, supostamente em decorrência do sexo.

Nesse caso, a corrente da reprodução cultural deixa de considerar, na fase inicial de sua elaboração, que a linguagem que veicula os elementos da cultura dominante e reproduz valores, crenças e representações da classe burguesa é a mesma que universaliza o masculino, tomando o homem como representativo da humanidade, formada desde sempre por homens e mulheres. Desconsidera também que a linguagem por meio de mecanismos gramaticais, historicamente, possibilitou tornar invisível a atuação das mulheres nos vários contextos socioeconômicos e político-culturais, contribuindo para a manutenção de relações desiguais entre os gêneros e para o reforço à internalização da dominação dos homens sobre as mulheres.

Nesse sentido, alguns estudiosos como Giroux (1986) e McRobbie (2012) apresentam uma crítica a essa corrente, argumentando que a complexidade das relações sociais não se explicaria apenas pelos mecanismos de dominação de uma classe sobre outra, mas também pela desigualdade das relações patriarcais e pela existência de forças que provocam e promovem resistências. 
Nesse sentido, destacamos que, se por um lado o modelo patriarcal adotado nas relações entre os gêneros se mantinha com a defesa de muitos, por outro lado, a inserção das mulheres no espaço público, que se amplia com a conquista do direito ao voto, sinaliza mudanças na imagem da mulher, até então limitada ao espaço privado. E, desse modo, abre perspectivas para o rompimento com antigos estereótipos com relação ao acesso feminino às estruturas de poder e às trocas de papéis sociais com a entrada do homem no espaço privado. No entanto, a crítica sobre a escola se mantém alheia aos movimentos de resistência e às conquistas das mulheres, insistindo na sua invisibilização.

Somente mais tarde, nos anos 1990, Bourdieu e Bernstein se debruçam sobre questões mais específicas da reprodução cultural e discutem a influência da escola na formação do conjunto de disposições e princípios relativos às relações sociais entre raças, religiões e gêneros, internalizados do mundo social por intermédio da cultura.

Assim, a sociologia de Bourdieu $(1995,2007)$ volta-se para as relações entre homens e mulheres e analisa a dominação masculina com base nas construções socialmente sexuadas do mundo que vão sendo incorporadas ao habitus. Para o autor, o mundo social, ao construir socialmente os sexos, ou os corpos, imprime no habitus um arbitrário cultural que diferencia homens e mulheres, valorando positivamente os atributos masculinos e negativamente os predicados femininos. Realiza, no dizer de Bourdieu, um trabalho de "socialização do biológico e de biologização do social", cujo funcionamento se assemelha ao de uma grande máquina que produz a dominação masculina com base na "diferença entre os sexos biológicos." Segundo o autor, o trabalho que o mundo social exerce sobre o homem e sobre a mulher "consiste em imprimir em seu corpo um verdadeiro programa de percepção, de apreciação e de ação que, na sua dimensão sexuada e sexuante funciona como uma natureza." (BOURDIEU, 1995, p. 145).

A naturalização do arbitrário cultural, assim como a visão dominante da divisão sexual se inscreve no habitus por meio da internalização de discursos, da presença e uso de objetos e das práticas em geral. Desse modo, os provérbios, os ditados, os cantos, os poemas, as representações gráficas do mundo, a estrutura do espaço, as divisões internas da casa, a organização do tempo, as posturas, as formas de andar, de sentar, de falar e de agir, os gestos asseguram a diferenciação e a dominação masculina, sem que esta tenha necessidade de justificação (BOURDIEU, 1995).

De igual modo, ao justificar a diferença entre os gêneros tomando como base as diferenças biológicas entre os sexos, o mundo social transforma o arbitrário cultural em natural e "a visão androcêntrica impõe-se como neutra e não tem necessidade de se enunciar em discursos que visem legitimá-la." (BOURDIEU, 2007, p. १८). 
Bourdieu (2007) afirma que os princípios da dominação masculina sobre as mulheres que se exerce no âmbito do privado só poderão ser compreendidos no âmbito das relações de poder. Destaca, ainda, que esses princípios não estariam sendo reproduzidos apenas no espaço doméstico e que a perpetuação da ordem dos gêneros é garantida pela atuação de três instâncias principais: a Família, a lgreja e a Escola, entendendo que esta última, "mesmo quando já liberta da tutela da lgreja, continua a transmitir os pressupostos da representação patriarcal [...]" (BOURDIEU, 2007, p. 104).

Assim, para o autor, a escola cumpre uma função na reprodução da diferença entre os gêneros que reforça o modelo dominante na estrutura familiar e na divisão do trabalho por meio da forma de organização sexuada que adota, da caracterização e hierarquização dos componentes curriculares e da orientação para as escolhas profissionais. Esses fatores, objetivamente orquestrados incorporam ao habitus os princípios definidores da ocupação do espaço público pelo homem e do espaço privado pela mulher. Nesse sentido, afirma que:

\footnotetext{
[..] através da experiência de uma ordem social 'sexualmente' ordenada e das chamadas à ordem explíitas que thes são dirigidas por seus pais, seus professores e seus colegas, e dotadas de princípios de visão que elas próprias adquiriram em experiências de mundo semelhantes, as meninas incorporam, sob forma de esquemas de percepção e de avaliação dificilmente acessiveis à consciência, os princípios da visão dominante que as levam a achar normal, ou mesmo natural, a ordem social tal como é e a prever, de certo modo, o próprio destino, recusando as posições ou as carreiras de que estão sistematicamente excluídas e encaminhando-se para as que lhes são sistematicamente destinadas. (BOURDIEU, 2007, p. 114).
}

Nesse sentido, a escola representa, para Bourdieu, uma das instâncias de inculcação das relações de dominação que se incorporam ao habitus mediante a dimensão simbólica da ação escolar que reproduz o arbitrário cultural masculino.

Também Bernstein, nos anos 1990, problematiza a inserção e a reprodução na escola de relações de poder que ultrapassam a diferenciação entre as classes sociais e têm motivação nas distinções entre categorias e no interior dessas próprias categorias, sejam estas constituídas por agentes representativos do gênero, da etnia, da idade, das capacidades, ou formadas pelos discursos - acadêmico, profissional, entre outros.

Bernstein (1996) adota o conceito de código para explicar como se dá a reprodução das classes sociais, entendendo os códigos como "dispositivos de posicionamento culturalmente determinados [...]", que "[...] regulados de acordo com a classe social posicionam os sujeitos relativamente às formas dominantes e dominadas de comunicação e às relações entre elas." 
Embora não tenham se debruçado especificamente sobre as questões relativas às diferenças entre os gêneros, os estudos do autor oferecem ideias e conceitos que possibilitam análises e compreensão de como a cultura escolar é marcada por essas relações. Desse modo, ao deter seus estudos sobre as relações de poder, o conhecimento e o discurso, Bernstein (1996, p. 39) afirma que "qualquer produção ou reprodução tem sua base social nas categorias e nas práticas sociais", cabendo aos diferentes conjuntos de categorias, distintos conjuntos de práticas especializadas.

Nessa perspectiva, o autor aproxima-se da noção de poder de Foucault (2007) e busca explicar como mediante o poder e o controle social as hierarquias e as diferenças são constituídas por meio de artifícios e princípios que classificam, regularizam e constroem os diferentes grupos sociais.

Bernstein argumenta que as vozes do discurso são arranjadas de forma hierárquica e não horizontal e dependem do grau de isolamento existente entre categorias, como se observa com relação aos gêneros. Assim, o isolamento dissimula as contradições do princípio de classificação do discurso com vistas a eliminar a arbitrariedade, de tal modo que "uma forte classificação de gênero tenta se justificar a si mesma com base no argumento de que se trata de uma ordem natural, não arbitrária." (BERNSTEIN, 1996, p. 46). Nesse caso, para o autor, o mito funcionalista estaria justificando a manutenção das diferenças de gênero de forma disfarçada, uma vez que essas relações são mostradas como resultado de diferenças de ordem biológica.

Para Bernstein (1996), no entanto, apesar de sua organização hierárquica, o discurso é entrecruzado por vozes diversas. Abriga a voz e suas subvozes. No caso da escola, na relação entre professor e aluno a voz dominante estaria com a categoria professor, enquanto entre os alunos existiriam subvozes representativas do gênero, da etnia, da raça, das religiões, das capacidades.

Observamos, assim, que os estudos de Bourdieu e de Bernstein nessa fase de elaboração ofereceram ferramentas conceituais para compreensão e explicação das desigualdades sociais ancoradas na diferenciação entre os gêneros e assinalam avanços observados dentro de um campo teórico - teorização curricular crítica -, suscitados pelas transformações sociais que passam a pautar a agenda social com novas questões tematizadas pelas ciências sociais e humanas.

Destacamos, contudo, que, embora a relação entre gêneros e currículo não tenha sido problematizada na fase inicial de suas respectivas obras, ${ }^{5}$ os anos 1970 correspondem ao período de efervescência dos movimentos feministas em vários países. Ademais, a produção dos

\footnotetext{
A Teoria do Sistema de Ensino como Violência Simbólica, desenvolvida por Bourdieu e Passeron, data de 1970, enquanto a Teoria dos Códigos de Bernstein é de 1975.
} 
estudos feministas começa a ocupar o espaço acadêmico, provocando a emergência do conceito de gênero na academia americana, nesse mesmo período. Observamos, nesse caso, que tanto os movimentos sociais quanto os movimentos acadêmicos já se encontravam em busca de respostas às questões suscitadas pela necessidade de construção da equidade entre gêneros.

Isso equivale a dizer que as contribuições teóricas desses dois autores para a compreensão das relações sociais de poder, implicadas na manutenção e reprodução das relações entre os gêneros, foram fundamentais, em especial pela incorporação da categoria cultura às análises dos processos educacionais. Essas análises começam a ser desdobradas nos estudos desenvolvidos sob a égide da corrente da resistência, à qual nos referimos aqui como segunda fase da teorização curricular crítica.

A corrente da resistência avança com relação às teorias da reprodução, na medida em que, além de denunciarem os mecanismos de reprodução cultural e social adotados pela escola, apontam também possibilidades de resistência e de contraposição ao discurso hegemônico. Esses estudos sinalizam propostas que, rompendo com o enfoque da neutralidade do currículo e avançando teoricamente com relação às teorias da reprodução, a partir da crítica a elas formulada, defendem uma educação para a emancipação, por meio de uma escola que ofereça oportunidades de desenvolvimento a todos que a buscam (GIROUX, 1986; FREIRE, 1987, 1989).

Entre as teorias da resistência o enfoque sobre as relações sociais de gênero aparece de diferentes formas. Assim, a pedagogia libertadora de Paulo Freire (1987, 1989), em sua fase inicial - nos anos 1960 -, focaliza intensamente as desigualdades sociais com foco na diferenciação entre as classes: opressores e oprimidos; denuncia os efeitos da educação bancária e propõe formas de superação da opressão. Na fase posterior do seu trabalho, o autor aponta outras formas de dominação e/ou subordinação, forjadas na e pela cultura, entre as quais estão as relações entre homens e mulheres. Nesse sentido, McLaren (1999, p. 36) argumenta que apesar de condenar duramente o racismo e o sexismo, Freire:

\footnotetext{
[...] não problematizou suficientemente suas concepções de libertação e de oprimido [...] raramente referiu-se às formas que a opressão assume quando se entrelaçam questões de etnia, classe social, orientação sexual [...] não abordou inteiramente a questão do privilégio masculino branco [...] $E$, às vezes em que efetivamente tratou dessas questões, seguidamente caiu em abstrações místicas, diminuindo, conseqüentemente, a profunda significação do patriarcado enquanto forma de opressão.
}

De acordo com McLaren (1999), Freire tinha consciência dessas omissões e havia começado a abordá-las em trabalho mais recente. Assim, em sua fase posterior de elaboração, a pedagogia freireana explicita sua rejeição a quaisquer formas de discriminação 
de gênero, de raça, de etnia, de classe, compreendendo-as como formas de transgressão ética. Argumenta que como transgressão da natureza humana não lhe cabe "justificativas genéticas, sociológicas, históricas ou filosóficas para explicar a superioridade da branquitude sobre a negritude, dos homens sobre as mulheres, dos patrões sobre os empregados." (FREIRE, 1996, p. 60). Assim, reconhece e denuncia a relação de dominação e os condicionamentos sociais e culturais aos quais os sujeitos estão expostos e caracteriza a opressão como ato de violência originado pelo exercício do poder.

Nos seus últimos escritos, Freire (1996) rompe com a universalização do masculino no uso da linguagem. Adota, em seus discursos, a diferenciação entre os gêneros, abolindo a generalização no masculino plural e a indeterminação dos sujeitos em seus discursos. Argumenta que "nem somos, mulheres e homens, seres simplesmente determinados nem tampouco livres de condicionamentos genéticos, culturais, sociais, históricos, de classe, de gênero, que nos marcam e a que nos achamos referidos." (FREIRE, 1996, p. 99).

Desse modo, o que se depreende do posicionamento do autor é que sua pedagogia oferece elementos para (re)criação, (re)invenção da cultura, compreendida por ele como palco de lutas e conquistas que se dão também por meio do currículo. Assim, o modelo pedagógico por ele criado veicula uma proposta de transformação social por meio da práxis educativa, pressupondo a autonomia docente como elemento estruturador do processo de mudança.

Por outro lado, o trabalho de Apple $(2002,2006)$ evidencia grande preocupação em demonstrar as vinculações existentes entre educação e currículo e as relações sociais de classe, de gênero, de raça, assim como mostra suas inquietações com as relações mais globais entre nações. Nesse caso, currículo e conhecimento são compreendidos como produtos das relações sociais, como artefatos históricos e sociais. Portanto, as relações entre estrutura econômica de um lado e currículo e educação de outro não se dão de forma direta, mas mediadas pela ação humana, que envolve outras múltiplas relações. De acordo com Apple (2002, p. 128):

[...] embora as relações patriarcais de gênero e as relações sociais capitalistas sejam muito dificeis de serem separadas, elas não podem ser reduzidas uma à outra [...] Assim, as práticas e significados ideológicos que vemos nas garotas, com todas as suas contradições, que tanto thes impõe limites quanto thes dão vigor, somente podem ser entendidos através de uma abordagem que veja como a economia do capital, a ideologia do patriarcado e as formas culturais da vida da classe trabalhadora reproduzem e contradizem umas às outras. 
Em consonância com o paradigma marxista, Apple atribui centralidade às relações de poder envolvidas na produção, distribuição e consumo dos recursos materiais e simbólicos selecionados no currículo. Admite a importância das relações de gênero e de raça no processo de reprodução cultural que se desenvolve por meio das vivências curriculares, sem, contudo, desconsiderar que "a escola é a arena para desenvolver essas relações." (APPLE, 2002, p. 113).

A pedagogia radical de Giroux (1986), por sua parte, toma como base as relações sociais de poder vivenciadas e reproduzidas na e pela cultura para analisar as desigualdades sociais e culturais presentes na escola. Para Giroux (1986), os seres humanos, ao fazerem história, constroem também restrições e são igualmente capazes de desfazêlas e transformá-las e, nesse sentido, o autor aponta limites do enfoque neomarxista do currículo, entendendo que a lógica que mobiliza a resistência pode estar ligada a interesses de classe, de gênero e/ou de raça. Dessa forma, sua "tentativa de superar as limitações dos enfoques marxistas ortodoxos leva a uma ênfase em raça e gênero junto com classe social, e a uma maior consideração dos setores cultural e político, além do econômico." (MOREIRA, 1990, p. 74). Para Giroux (1986, p. 87), alguns desses trabalhos

\footnotetext{
[...] dizem muito pouco a respeito das maneiras complexas pelas quais a consciência e a cultura interagem, a respeito de como os alunos, operando a partir das especificidades de gênero, raça e classe, oferecem resistência aos mecanismos de controle social e de dominação, nas escolas.
}

De acordo com Zuin e Pucci (1999, p. 30), em Giroux “as categorias de gênero, raça, minorias interagem com a de classe social, na tentativa de captar mais de perto os conflitos, as contradições sociais e suas manifestações de rebeldia, de resistência, de organização, de luta." Dessa forma, Giroux sinaliza a necessidade de ampliação da compreensão sobre as formas de contestação e de resistência como elementos das lutas culturais que se desenvolvem na escola e, em especial no currículo, aproximando-se do enfoque dado aos estudos de currículo pela teorização pós-crítica.

Nessa trajetória, o percurso registrado no interior da teorização educacional crítica avança e incorpora outras categorias às análises sobre o currículo. Assim, categorias como resistência, libertação, emancipação passam a compor essas análises e a anunciar possibilidades de elaboração de uma contracultura escolar e/ou curricular, ao mesmo tempo que agrega às apreciações elementos da cultura como constituintes de desigualdades sociais.

Nesse sentido, sublinhamos a relevância desses estudos para compreensão dos aspectos políticos envolvidos nos fenômenos educativos vivenciados no interior da escola, em 
especial para o desenvolvimento dos vínculos que viriam a se estabelecer entre os estudos de currículo e os estudos de gênero a partir da teorização pós-crítica do currículo.

\section{GÊNERO NA TEORIZAÇÃO PÓS-CRÍTICA: A LINGUAGEM COMO CONSTRUTORA DE SUBJETIUIDADES, IDENTIDADES E REPRESENTAÇÕES}

As teorias pós-críticas - teorização em que os conteúdos e as formas textuais e discursivas assumem centralidade - oportunizam ampliar a compreensão sobre as relações de poder que atravessam os fenômenos sociais, alargar a análise da dinâmica de classe na produção de desigualdades sociais e de relações hierárquicas na sociedade capitalista, além de possibilitarem um deslocamento na maneira de conceber o currículo, ao adotarem o conceito de discurso em suas formulações.

Assim, referenciada na noção foucaultiana de poder, a teorização pós-crítica possibilita compreendê-lo como força que se desloca em várias direções, assumindo variadas formas e espalhando-se em toda a rede social. 0 poder não se constitui um mecanismo de dominação homogênea, não se expressa de forma unilateral, mas circula e funciona em cadeia e se exerce em rede, distribui-se passando por todos os sujeitos, ainda que de forma assimétrica (FOUCAULT, 2007).

As teorias pós-críticas também possibilitam ampliar o entendimento sobre algumas categorias presentes na teorização crítica, possibilitando estender a compreensão sobre os processos de dominação, a concepção de política e o conceito de ideologia nela presentes. Assim, de acordo com Silva (2007, p. 146):

\footnotetext{
[...] a concepção de identidade cultural e social desenvolvida pelas teorias pós-críticas nos tem permitido estender nossa concepção politica para muito além de seu sentido tradicional - focalizado nas atividades ao redor do Estado. [...] a análise da dinâmica de poder envolvida nas relações de gênero, etnia, raça e sexualidade nos fornece um mapa muito mais completo e complexo das relações sociais de dominação do que aquele que as teorias críticas, com ênfase quase exclusiva na classe social, nos tinham anteriormente fornecido.
}

Essas ideias favorecem a compreensão sobre os mecanismos de dominação forjados com base nas diferenças culturais, bem como sobre o engendramento dos movimentos de contestação e de reação presentes nas relações sociais de gênero no interior da escola. 
Desse modo, a teorização pós-crítica - Estudos Culturais, Estudos Pós-Colonialistas, Pós-Modernistas, Pós-Estruturalistas, Estudos Feministas, entre outros - destacam as contribuições da teoria crítica do currículo, reconhecem as desigualdades de classes sociais como instituidoras de condições assimétricas de acesso aos bens materiais e de participação social, consideram a relevância da orientação para a formação do comportamento crítico. Contudo, ampliam o debate relativo às relações de gênero no currículo, ao apontarem novas formas de olhar a cultura, a sociedade e a escola.

Sua aproximação com a perspectiva multiculturalista do currículo dialoga com o entendimento de que o currículo está profundamente entrelaçado aos processos culturais do contexto do qual emerge e no qual se situa. Nesse entrelaçamento a cultura é compreendida como processo histórico, dinâmico e complexo, inferindo que seus elementos são mutáveis, que qualquer teorização sobre o currículo diz respeito a um tempo-espaço definido, expressa um pensamento plural e não uniforme (PACHECO, 2005).

Nesse sentido, as relações culturais, como concebidas pela teorização pós-crítica, supõem a pluralidade, mas sem perder de vista a hierarquização dos valores culturais e o seu atravessamento por mecanismos de poder, que se distribuem de forma assimétrica. Assim, em razão de suas relações com a cultura e com as diferenças culturais, o multiculturalismo carrega a marca da polissemia na qual está envolto.

Porém, cabe-nos sublinhar que, não obstante os vários sentidos assumidos pelo multiculturalismo, para a teorização pós-crítica este se afasta tanto da perspectiva assimilacionista, segundo a qual a(s) cultura(s) dos grupos discriminados deveria(m) se integrar à cultura hegemônica, quanto da perspectiva diferencialista, que, ao enfatizar o reconhecimento das diferenças sem problematizá-las, defende a formação de comunidades culturais homogêneas como garantia do direito à liberdade coletiva. Ou seja, de acordo com a primeira concepção, as culturas não hegemônicas deveriam se integrar à matriz cultural considerada legítima, em nome de um projeto comum de sociedade que nega ou silencia as diferenças. Por sua vez, a segunda concepção, em nome de um suposto reconhecimento das diferenças, promove a manutenção do apartamento entre grupos de diferentes identidades culturais, aproximando-se de uma concepção essencialista.

Em contraposição, a teorização pós-crítica "propõe um multiculturalismo aberto e interativo, que acentua a interculturalidade por considerá-la mais adequada para a construção de sociedades democráticas, pluralistas e inclusivas, que articulem políticas de igualdade com políticas de identidade." (CANDAU, 2008, p. 22). Coloca a cultura no centro das reflexões sobre as políticas e práticas curriculares e, dessa forma, pauta-se pela ideia de que as diferenças, produzidas na e pela cultura, são constituídas mediante a linguagem. 
Isso porque a linguagem, em permanente circulação entre os sujeitos, exerce o poder de nomear, classificar, hierarquizar, difundir representações, forjar identidades e subjetividades. Contudo, se à linguagem cabe a missão de homogeneizar as formas de apresentação e os comportamentos sociais dos sujeitos, a ela cumpre também a função de diferenciar, uma vez que por meio da linguagem é possível evidenciar, mas também ocultar, alardear ou silenciar, iluminar ou opacificar, (in)visibilizar e (des)dizer.

As linguagens, em especial a oral e a escrita, compõem os currículos escolares, estando incorporadas ao fazer cotidiano de estudantes e professores, como principal instrumento da transmissão dos conteúdos curriculares, da realização das interações sociais e da construção de representações e saberes, atravessados por relações de poder.

A vista disso, as diferenças culturais passam a ser compreendidas e problematizadas no interior de um sistema de representação que produz as diferenças também por intermédio do currículo. 0 currículo, por sua vez, tratado sob esse enfoque passa a ser entendido como elemento da cultura que expressa concepções de sujeito e de sociedade referentes a um tempo e a um espaço definidos. Assim, para as teorias póscríticas, o currículo é também formador de subjetividades e de identidades, entres as quais estão as identidades de gênero, ou seja, em uma mesma classe social coexistem diferentes identidades que assumem posições assimétricas em razão das relações de poder que se estabelecem no seu interior.

Destacamos, no entanto, que essa compreensão se afasta da ideia de identidade como essência ou identidade unitária, forjada com referência no gênero como determinação biológica. Costa (1998, p. 174) sugere "uma abordagem que não fixe uma identidade, que permita uma análise da fluidez da identidade, a partir de uma perspectiva relacional." Sublinha que essa abordagem não caminha na direção da totalização, da universalização do sujeito, mas, antes, considera a multiplicidade de relações constitutivas dos gêneros, de forma a favorecer estudos sobre a pluralidade "de mulheres e homens, recortados pelas diferenças de raça, classe social, idade, orientação sexual, nacionalidade, etnia, religião, etc." (COSTA, 1998, p. 187-188).

Os estudos de gênero, por seu turno, incorporam a dimensão relacional das construções do masculino e do feminino como constituição histórica e cultural, que assume diferentes configurações em diferentes sociedades ou em uma mesma sociedade em momentos diversos. Trata-se de um campo de estudos que tem sua gênese na constatação e compreensão de que as diferenças culturais de gênero têm servido de base para a construção de relações de desigualdade social.

Em consequência, a teorização curricular pós-crítica sinaliza possibilidades de construção de um currículo que possa problematizar a ocupação de diferentes lugares 
sociais por homens e mulheres, refletir sobre o cotidiano desses sujeitos e questionar a constituição dos significados produzidos pelas diferenças entre gêneros.

\section{CHEGADA A UM PONTO DA CAMINHADA: APROXIMAÇÕES CONCLUSIUAS}

A trajetória dos estudos sobre currículo e sua relação com o gênero como categoria de análise nos impele a destacar as contribuições dos estudos culturais aos estudos curriculares e de gênero. Isso porque esses estudos favorecem a compreensão sobre os mecanismos de dominação forjados com base nas diferenças culturais, bem como sobre o engendramento dos movimentos de contestação e reação presentes entre os gêneros no interior da escola e na sociedade mais ampla.

Assim, na tentativa de responder qual o espaço reservado na teorização curricular - tradicional, crítica e pós-crítica - para as discussões sobre as relações sociais de gênero, podemos inferir que o trato com as questões de gênero estiveram ausentes da teorização curricular tradicional ou não crítica em razão de sua pretensão à neutralidade e objetividade, próprias do modo de produzir conhecimento referenciado na racionalidade técnico-científica. Embora a escola tenha tornado diferentes os que nela adentravam dos que a ela não tinham acesso, a exemplo de pobres, negros, mulheres e adultos, essas diferenças - de classe, raça/etnia, sexo, idade - foram de tal forma naturalizadas pelo paradigma da racionalidade científica que as desigualdades sociais, além de não serem problematizadas, são apresentadas como naturais pela teorização curricular não crítica. Sua vinculação à dimensão técnico-científica e seu apartamento das questões sociais resulta na construção de uma teorização da qual o gênero está ausente.

De outra parte, a teorização crítica, desde o seu nascedouro, problematiza as relações sociais envolvidas na tomada de decisões sobre a escola, desnaturaliza a pretensa neutralidade do currículo e denuncia suas implicações com a reprodução da sociedade capitalista, revelando-o como um campo de disputas. Contudo, na sua fase inicial a ênfase na categoria classe social, tomada como base para análise dos fenômenos educacionais, acaba por afastar essa teorização de outros elementos promotores de desigualdades, a exemplo das diferenças geradas na e pela cultura, entre as quais estão as diferenças entre gêneros. Com isso, a teorização crítica nessa fase parece supor que as desigualdades sociais são produzidas apenas pela divisão da sociedade em classes, desconsiderando que elementos da cultura promovem desigualdades no interior de uma mesma classe. Desse modo, a categoria 
gênero também não se faz presente nas análises da corrente crítica da reprodução social, que constitui a primeira fase da teoria crítica a investigar os fenômenos educacionais.

Em contrapartida, o gênero se insere definitivamente no discurso curricular a partir do entendimento de que a cultura como elemento constituído e constituinte de diferenças é também instituidora de desigualdades sociais. Assim, na sua segunda fase a teorização crítica, ao considerar a dimensão histórica da cultura na constituição da sociedade, aproxima-se das questões sociais envolvidas nas experiências curriculares, passando a abarcar questões relativas às relações entre gêneros presentes no interior da escola. À vista disso, anuncia mudanças no enfoque sobre o currículo, sobretudo ao se aproximar da perspectiva multiculturalista, acerca da qual se debruça a teorização pós-crítica.

A teorização pós-crítica, por sua vez, atribui centralidade à cultura e, tomando-a em sua dimensão plural, considera que mecanismos de poder atravessam as relações culturais e compreende a linguagem como constituinte das diferenças entre os sujeitos. Nesse sentido, oferece as ferramentas para que as relações de gênero sejam problematizadas na escola e os currículos escolares possibilitem um diálogo com a vida cotidiana dos estudantes. Isso porque os estudos pós-críticos compreendem o currículo como formador de subjetividades, de identidades e de representações. Estas, por sua vez, não sendo fixas, estão em permanente processo de construção, desconstrução e reconstrução.

\section{REFERÊNCIAS}

ALMEIDA, J. S. Mulher e educação: a paixão pelo possivel. São Paulo: Fundação Editora da Unesp, 1998.

ALTHUSSER, L. Aparelhos ideológicos do Estado. 2. ed. Rio de Janeiro: Graal, 1985.

APPLE, M. W. Educação e poder. Porto Alegre: ArtMed, 2002.

APPLE, M. W. Ideologia e currículo. Porto Alegre: ArtMed, 2006.

BAUDELOT, C.; ESTABLET, R. L'école capitaliste em France. Paris: François Maspero, 1971.

BERNSTEIN, B. A estruturação do discurso pedagógico: classe, código e controle. Tradução: Tomaz Tadeu da Silva e Luiz Fernando G. Pereira. Petrópolis, RJ: Vozes, 1996.

BERTICELLI, I. A. Currículo: tendências e filosofia. In: COSTA, M. V. 0 Currículo nos limiares do contemporâneo. 3. ed. Rio de Janeiro: DP\&A, 2003.

BOURDIEU, P. A dominação masculina. 5. ed. Tradução: Maria Helena Kühner. Rio de Janeiro: Bertrand Brasil, 2007. 
BOURDIEU, P. A dominação masculina. Educação e Realidade, n. 20, jul./dez. 1995.

BOURDIEU, P.; PASSERON, J. C. A reprodução: elementos para uma teoria do sistema de ensino. Tradução: Reynaldo Bairão. Rio de Janeiro: Francisco Alves, 1982.

CANDAU, V. M. Multiculturalismo e educação: desafios para a prática pedagógica. In: MOREIRA, A. F.; CANDAU, V. M. (org.). Multiculturalismo: diferenças culturais e práticas pedagógicas. 2. ed. Petrópolis, RJ: Vozes, 2008.

CARVALHO, M. E. P. Uma agenda de pesquisa, formação humana e docente em gênero e educação. In: PIZZI, L. C. V.; FUMES, N. L. F. (org.). Formação do pesquisador em educação: identidade, diversidade, inclusão e juventude. Maceió: Edufal, 2007.

COSTA, R. G. De clonagens e de paternidades: as encruzilhadas do gênero. Cadernos Pagu, Campinas, SP: Unicamp, n. 11, p. 157-199, 1998.

ERGAS, Y. 0 Sujeito mulher. 0 Feminismo dos anos 1960/1980. In: PERROT, M.; DUBY G. (org.). História das mulheres no ocidente: o século XX. Porto: Afrontamento; São Paulo: Ebradil, 1991. v. 5.

FOUCAULT, M. Microfísica do poder. 23. ed. Tradução: Roberto Machado. Rio de Janeiro: Edições Graal, 2007.

FREIRE, P. Educação como prática da liberdade. 19. ed. Rio de Janeiro: Paz e Terra, 1989.

FREIRE, P. Pedagogia da autonomia: saberes necessários à prática educativa. 28. ed. Rio de Janeiro: Paz e Terra, 1996.

FREIRE, P. Pedagogia do oprimido. 17. ed. Rio de Janeiro: Paz e Terra, 1987.

GIROUX, H. Teoria crítica e resistência em educação. Tradução: Ângela Maria B. Biaggio. Petrópolis, RJ: Vozes, 1986.

GOODSON, I. F. Currículo: teoria e história. 5. ed. Tradução: Attilio Brunetta. Petrópolis, RJ: Vozes, 2002.

HORKHEIMER, M. Teoria tradicional e teoria crítica. In: HORKHEMMER, M.; ADORNO, T. W. Textos escolhidos. Tradução: Zelijko Loparié et al. 5. ed. São Paulo: Nova Cultural, 1991. (Coleção Os Pensadores).

KÄPPELI, A. Cenas feministas. In: PERROT, M.; FRAISSE, G. (org.). História das mulheres no ocidente: 0 século XIX. São Paulo: Ebradil, 1991. v. 4.

MCLAREN, P. Utopias provisórias: as pedagogias críticas num cenário pós-colonial. Tradução: Helena Beatriz M. de Souza. Petrópolis, RJ: Vozes, 1999.

MCROBBIE, A. Pós-marxismo e Estudos Culturais. In: SLVVA, T. T. (org.). Alienígenas em sala de aula: uma introdução aos estudos culturais em educação. 10. ed. Petrópolis, RJ: Vozes, 2012. 
MOREIRA, A. F. B. Sociologia do currículo: origens, desenvolvimento e contribuições. Em Aberto, Brasilia, DF, ano 9, n. 46, p. 73-83, 1990.

PACHECO, J. A. Escritos curriculares. São Paulo: Cortez, 2005.

PUCCl, B. (org.). Teoria crítica e educação: A questão da formação cultural na Escola de Frankfurt. 3. ed. Petrópolis, RJ: Vozes, 2003.

SAMARA, E. M. et al. (org.). Gênero em debate: trajetória e perspectivas na historiografia contemporânea. São Paulo: EDUC, 1997.

SCOTT, J. Gênero: uma categoria útil de análise histórica. Educação e Realidade, Porto Alegre, v. 16, p. 5-22, jul./dez. 1990.

SILVA, T. T. Apresentação. In: PUCCl, B. (org.). Teoria crítica e educação. 3. ed. Petrópolis, RJ: Vozes, 2003.

SILVA, T. T. Documentos de identidade: numa introdução às teorias do currículo. 2. ed. Belo Horizonte: Autêntica, 2007.

SILVA, T. T. Identidades terminais: as transformações na política da pedagogia e pedagogia da política. Petrópolis: Vozes, 1996.

SILVA, T. T. Teorias do currículo: uma introdução crítica. Porto: Porto Ed., 2000.

TERIGl, F. Notas para uma genealogia do curriculum escolar. Educação e Realidade, v. 21, n. 1, p. 159१८6, jan./jun. 1996.

TYLER, R. W. Princípios básicos de currículo e ensino. Tradução: Leonel Vallandro. Porto Alegre: Globo, 1974.

ZUIN, A. A. S.; PUCCl, B. A pedagogia radical de Henry Giroux: uma crítica imanente. Piracicaba: Unimep, 1999.

Endereços para correspondência: Rua Carpina, n. 102, Bairro Jardim São Paulo, 50781-660, Recife, Pernambuco, Brasil; eletafreire.ufpe@gmail.com 
